\section{Definitive Cell Biology}

The Biology of the Cell Cycle. By J. M. Mitchison. Pp. $\mathrm{v}+313$. (Cambridge University Press: London, December 1971.) $£ 4.60$ cloth; $£ 1.60$ paper.

PROFESSOR Mitchison is one of the foremost analysts of the cell cycle and this book is the distillation of many years of thought and experiment in this field. It is a definitive work without any serious present competitior and unlikely to be surpassed in the foreseeable future. There are probably few scholars able to deal with so wide a range of material and fewer still able to deal with it critically.

The first two sections deal with methods for the study of the cell cycle: single cell techniques and synchronous cultures. The range and power of the various techniques are accurately discussed, and so are the uncertainties of interpretation introduced by the techniques themselves. It is difficult to think of any other source where the methodology for the study of the cell cycle is so succinctly and intelligently discussed. Two sections then follow dealing with DNA synthesis in a wide range of experimental material, from prokaryotes to higher animals. These sections may well be the most satisfactory ones, at least for those readers who are troubled by continuing uncertainty. For while we are still unsure of the enzymic basis of DNA replication and have no idea at all of the chemical nature of the signals that initiate and terminate it, we none the less do have a solid body of reproducible experiment on the geography and timing of DNA synthesis at various levels of cellular organization. This body of material Mitchison ably reviews. There is a single section on RNA synthesis, and, in some respects, this is the least satisfactory part of the book. For this the author can hardly be blamed; for while, over the years, experiments on DNA synthesis have become increasingly precise and thoughtful, experiments on RNA synthesis in whole cells are still very often difficult to interpret, and many experimenters in this field, despite prolonged instruction, remain incorrigibly silly. To the section on cell growth and protein synthesis and that on enzyme synthesis Mitchison brings an authority derived from his own experimental experience. He has perhaps done more than any other single worker to give precision to experiments on cell growth, and his recent work on periodic fluctuations in enzyme activity during the cell cycle has raised questions which may prove to be of fundamental importance to our understanding of how the synthesis of proteins really is regulated. In these two sections the personal commitment of the writer shows through, and it enlivens what might otherwise be very difficult subjects to dis- cuss in an interesting way. The book ends with a collection of observations about cell organelles, respiration and pools and a thoughtful discussion on the control of cell division.

There is no doubt that this work will be of the greatest value to all those interested in cell biology; and it will be indispensable to those who have to teach the subject. The book is well produced, well indexed and contains, in addition to the text, about a thousand references carefully chosen and accurately documented.

HENRY HARRIS

\section{Aardvark to Zebra}

East African Mammals: An Atlas of Evolution in Africa. By Jonathan Kingdon. Pp. $\mathrm{x}+446$. (Academic: New York and London, July 1971.) $£ 12 ; \$ 35$.

THE mammals of East Africa have for long been a focus of attention. The astonishing abundance and diversity of large mammals attracted first the hunter and more recently the ecologist and the tourist, while the attentions of naturalists and of veterinary and medical workers have resulted in the equally diverse smaller mammals being better known than those of most parts of the tropics. But among the long sequence of literature that has eilsued there has never been any attempt at a comprehensive synthesis. For the resident biologist or the visiting naturalist alike there is virtually nothing a vailable between the very superficial treatment of the field guide (and that only very recently) and the highly fragmentary confusion of papers on detailed taxonomic or ecological studies.

This volume is the first of three that are planned to cover all species of East African mammals. It deals with the primates and a number of small orders, namely the hyraxes, the pangolins, the aardvark and the dugong. The author makes it clear that the style and approach of each volume will vary-the second will contain the smaller mammals with emphasis on distribution and taxonomy, the third the larger species with special reference to their potential for exploitation. This first volume includes only thirty-two of the 360 or so species involved. This alone will dictate a very different approach to the remainder if the work is to be kept within bounds.

The introductory chapters include very useful and relevant accounts of the East African environment, with special emphasis on vegetation; and of the history and zoogeography of the East African mammal fauna. An appendix on the anatomy of mammals (dealing only with the skeletal and muscular systems) is less relevant but reflects the approach of the author throughout the following systematic section which is liberally illustrated with drawings of skeletons and of superficial dissections.
The latter in particular stem from the author's approach as an artist and are presumably intended to illustrate the evolutionary theme inherent in the title. But there is little correlation here between illustration and text which does not deal with the characters illustrated, while those aspects of structure that are more immediately relevant in terms of adaptation to the local environment, such as teeth and alimentary anatomy, are not illustrated.

In addition to these anatomical figures each species is illustrated by a beautifully executed black-and-white drawing supplemented in most cases by numerous "sketches from life". Four coloured plates depict very beautifully the intriguing array of pattern and colours in Colobus and Cercopithecus, although again one of these represents a diversion, dealing with a West African group. Distribution maps for each species are a very valuable feature and provide a sound and objective basis for zoogeographical analysis, an exercise that is too often based on those highly selected data that happen to fit the arguments.

The text covers many aspects of each species including distribution, variation, ecology and behaviour, but without any subdivision. In view of the overall evolutionary approach it seems a curious and irritating omission that no details are given of the variability in the transition zones where the two subspecies (or species?) of baboons and of vervet monkeys meet, both of them very intriguing situations for the student of speciation.

On the one hand, this volume must be welcomed as the only available synthesis of data on the mammals of East Africa, and a very valuable one at that, containing a wealth of personal experience of the subject. On the other hand, one must regret that the addition of a great deal of material of very marginal relevance to the main issue has enlarged the work to an extent and a price that will gravely limit its use, and that the data are not better organized for ease of retrieval and reference. In many respects it is a luxury but one that many will enjoy.

G. B. CORBET

\section{Death of the Whale}

The Blue Whale. By George L. Small. Pp. xiii +248 . (19 plates.) (Columbia University: New York and London, June 1971.) $\$ 9.95$.

ThE largest animal that has ever lived on this planet is virtually extinct. It is common knowledge that the blue whale has been hunted to this sorry state by that rapacious predator, man. This situation developed because the International Whaling Commission has no real power; and this impotence stems from the fact that the resources of the 